\title{
Fit of Professional Setting and Regional Industrial Structure of Financial Colleges in the Greater Bay Area from Industry-Education Integration
}

\author{
Shuyuan Liu (i) \\ Guangdong University of Finance \& Economics, Guang Dong 510320, China \\ Correspondence should be addressed to Shuyuan Liu; law_sharol@gdufe.edu.cn
}

Received 4 December 2021; Revised 25 December 2021; Accepted 27 December 2021; Published 31 January 2022

Academic Editor: Xin Ning

Copyright ( $\odot 2022$ Shuyuan Liu. This is an open access article distributed under the Creative Commons Attribution License, which permits unrestricted use, distribution, and reproduction in any medium, provided the original work is properly cited.

\begin{abstract}
Promoting the initiative and subjectivity of the two main bodies of schools and enterprises, as well as fully exploiting their synergy in practice, is a necessary prerequisite for reflecting the benefits of school-enterprise integration, and without it, China's vocational education cannot improve the quality of professional and technical personnel training. Simultaneously, it allows for high-level economic and social development. This is also the focus and challenge of current vocational and technical education reform and innovation. We discovered that the integration of industry and education, as well as school-enterprise cooperation, has made significant progress in City C's higher vocational colleges through questionnaire surveys and on-site interviews: the cooperation mechanism has been steadily established and innovated, the talent joint training model is diverse; the level of cooperation between the two parties has been continuously improved; the benefits of enterprise cooperation are complementary, and $s$ The current situation is "schools are hot and enterprises are hot," and both supply and demand are booming, contrary to the empirical view that the education industry integrates "schools are hot and enterprises are cold." The engineering talent training industryeducation integration collaboration model is to establish and combine multiple case studies to illustrate its application scenarios, and then propose the characteristics of the collaboration model and the level analysis of the collaboration elements based on different systems, dynamics, and dynamic training models. This study collects data through questionnaire surveys and investigates the synergistic elements using the fs QCA empirical analysis method. These synergistic elements can help the integration project be more effective. Reproducible guidance is provided by various types of integration projects. Finally, in light of the current state of talent training in the integration of production and education, this research suggests three countermeasures: government optimization of top-level design, hierarchical implementation of the collaborative main model, and project implementation scope to coordinate school and enterprise path selection.
\end{abstract}

\section{Introduction}

Education reform initiatives have continued to nurture and deliver a large number of high-quality talents for economic and social development, accelerating the development of modern industrial systems [1]. Looking around the world, most education systems have adopted a standardized direct teaching model, resulting in graduates who enter the workforce early in their careers in repetitive manufacturing jobs [2]. Despite the fact that some universities have taken positive steps such as new designs, adaptations, and transformations in various subject areas, many education systems continue to rely on direct teaching and passive learning by teachers, and the outdated teaching organization and management model is unable to meet the large number of demands emerging in the new context in a timely manner [3]. Students have a poor understanding of old engineering situations and a better understanding of new engineering scenarios as a result of the training gap in practice; in general, students lack both an understanding of the product process in old engineering practice and knowledge of digital product process and modeling on the old process. As a result, students are unable to apply what they have learned in school to their current projects, i.e., school-trained talents 
are unable to meet the needs of industry [4]. Breakthroughs have been made in cutting-edge industries such as new energy, information, biology, energy conservation, and environmental protection with the advent of the Industry 4.0 era [5]. This is a fantastic opportunity for China's manufacturing to develop, transform, and upgrade, but it's also a daunting challenge with many unknowns. It lays out new and difficult requirements for China's higher engineering education, particularly for the development of engineering talent to meet the demands of emerging technological breakthroughs and new industrial development.

New engineering talents must have the ability of multiple characteristics such as "practical, crossover and comprehensive", where "practical" refers to the ability to do and practice, "crossover" focuses on that the knowledge of engineering talents should be more "crossover and broad", and "comprehensive" emphasizes that engineering talents should not only have the background of engineering field but also be involved in economy and management [6]. The "practical" refers to hands-on and practical ability, "crossover" focuses on that the knowledge of engineering talents should be more "cross and broad", and "comprehensive" emphasizes that engineering talents should not only have the background of engineering field but also be involved in economic and management fields. In a word, the demand for engineering talents in the industry and the era has changed tremendously, and the new industry needs high-quality engineering talents with both practical expertise and crosscomprehensive knowledge background [7]. However, at the same time, influenced by many factors such as development concept, operation mechanism and action guideline, the original education supply side of engineering talents cultivation and industrial demand side still cannot fit well in terms of talent structure, quality and level, and the problem of separation of "production" and "education" still the problem of separation of "production" and "education" still exists. With the passage of time, the width and depth of the reform of the integration of industry and education have gradually increased [8]; nowadays, not only the pilot projects are required to be carried out extensively, but also the pilot effects are gradually pursued. However, the effectiveness of talent cultivation in existing industry-education integration projects is average, and the problem of mismatch between supply and demand for engineering talents remains serious, despite improvement: according to the National Development and Reform Commission's estimates, China will have a large shortage of engineering talents by 2020 , with a shortage of 3 million in mechanical engineering and new material fields, for example. The reason for this is that industry and education integration faces the following challenges: the lack of government functions, blurred authority boundaries, and unclear role, which leads to a lack of property rights protection for integration project output results and systematic long-term legal and policy coordination mechanisms for the integration of industry and education; the lack of intrinsic motivation of enterprises, which is primarily due to the fact that enterprises do not clearly feel empowered by the integration projects and do not do anything about it; the lack of intrinsic motivation of enterprises, which is primarily due to the fact that enterprises do not clearly feel empowered by the integration projects and do nothing The reason for this is that enterprises do not feel empowered by integration projects and do not benefit from them, resulting in the "school is hot, enterprise is cold" phenomenon; schools lack the foundation to maintain industry-education integration, and the driving force of change is insufficient, and the talent training model of a thousand schools has not been fundamentally changed; the voice of industry is insufficient, resulting in ambiguity of the issue. These issues point to the fact that China's existing educational system has remained largely unchanged. The emergence of these issues demonstrates that all participants in China's existing industryeducation integration have failed to "collaborate" effectively, i.e., they have not truly achieved "integration" at the level of actions and projects, and the industry-education integration projects have not fully exploited their advantages of improving the effectiveness of engineering talent training [9]. To summarize, there is a mismatch between industry demand and university supply, implying that universities must respond to new economic and societal demands, cultivate engineering talent with practical expertise and cross-cutting knowledge backgrounds, and comprehend real industrial scenarios based on the characteristics of various disciplines [10].

At the same time, universities and enterprises have made many attempts to build laboratories and R\&D platforms together in the integration projects. However, the phenomenon of "two skins" between industry and education still exists, and the problem of integration has not been solved fundamentally. Therefore, there is an urgent need for an industry-education integration model that can realize a comprehensive and substantial deep integration of resources, personnel, technology, management and culture, as well as a special implementation path that fits the project background and can help improve the effectiveness of industry-education integration projects. As a key path to solve the problem of "two skins" between talent supply and industrial demand, the integration of industry and education has been carried out on a pilot basis nationwide. Based on this background, this study will focus on the core issue of how to improve the effectiveness of industry-education fusion engineering talent cultivation project, and explore the theory and practice on this issue. The following is the research topic for this paper: To construct the integration of industry-education engineering talent cultivation mode, first identify the synergistic elements of the integration of industry-education engineering talent cultivation from the materials of the integration of industry-education project, then thoroughly analyze the connotation concept of the synergistic elements as well as the inner connection between the elements. Second, an empirical analysis of the path of industry-education engineering talent cultivation is conducted in order to investigate the combination of synergistic elements for both industry and education to achieve high project effectiveness in various contexts. Finally, countermeasures and suggestions are proposed from the perspective of multiple synergistic subsystems, such as enterprises, 
universities, and government, based on the existing problems of industry-education integration, as well as the previous research findings, to help improve the effectiveness of the industry-education integration talent cultivation project.

The main contributions of this article are as follows:

(1) This article promotes the initiative and subjectivity of the two main bodies of school and enterprise, and gives full play to the synergy of the two in practice, which reflects the necessity of the efficiency of school-enterprise integration.

(2) Combine multiple cases to illustrate its application scenarios, and then propose the characteristics of the collaboration model and the level analysis of the collaboration elements according to different systems, dynamics, and dynamics.

(3) This study collects data through questionnaire surveys and uses fs QCA empirical analysis methods to investigate synergistic factors. These synergistic elements can help integrate projects more effectively. Various types of integration projects provide repeatable guidance. Finally, in view of the current situation of talent training for the integration of production and education, this research proposes three countermeasures: government optimization of the top-level design, hierarchical implementation of the collaborative main model, and school-enterprise coordination of the scope of project implementation.

\section{Related Work}

Although academics have been conducting research on the cooperation between schools and enterprises, government and other multi-subjects for a long time, the analysis of common patterns and characteristic paths for the training of talents in industry-education integration engineering in academia is still not deep and mature compared with the extensive piloting of domestic industry-education integration projects. Therefore, this study intends to contribute to the research related to the cultivation of talents in industryeducation integration projects. Specifically, based on the synergy theory, the main theoretical contributions to analyze the modes and paths of talent cultivation in the integration of industry-education engineering are as follows: First, the synergy mode obtained in this study is a generic mode for the integration of industry-education projects summarized from several cases, and the saturation test is done using typical cases, which is applicable to the pre-start, mid-term construction, post-term evaluation and the summary of the innovation method of the synergy mode for the existing integration of industry-education projects [11]. It enriches the systematic exploration of the integration model of industry-education integration. Secondly, this study makes up for the lack of theoretical research on the integration of industry-education, takes the synergy theory as the entry point to study the common patterns and characteristic paths of the integration of industry-education, and provides experiences and innovative structures for the future in-depth exploration of the topics related to the integration of industry-education. Finally, this study is an innovative attempt of management research, qualitative research and quantitative research by combining the integration of industry-education with rooted research and fs QCA [12].

According to the current state of development of education and industry integration in China, there are many projects and pilot projects, but the quality of these integration projects varies, which means that the project's effect cannot be guaranteed, i.e., the cultivation of engineering talents cannot adequately meet the needs of industry, which has a significant impact on industry's progress and the longterm positive interaction between education and industry. To ensure the smooth and effective implementation of industry-education integration projects, a stable and systematic model is required [13]. The results of this study's innovative research on the synergistic model of industryeducation integration can effectively describe, evaluate, and improve existing industry-education integration projects, and the conclusions based on the effective path analysis can help the participating industry-education parties quickly find the appropriate development path based on their own situation, thereby improving the effectiveness of engineering personnel training [14]. At the same time, this study offers targeted countermeasure recommendations for the government, industry, and education, in order to promote the effective expansion of industry-education integration projects and the cultivation of engineering talent that meets the needs of industries in the new industry. Most academic studies on industry-education integration focus on refining the models and problems of industry-education integration through case studies, but few studies have looked at the logic behind industry-education integration from a theoretical perspective, particularly the synergy theory.

Based on synergy theory, this study uses the method of rooted research to extract factors related to the integration of industry-education from multiple project case materials and refine synergistic elements, which are then summarized into common patterns to provide a solid theoretical foundation and practical experience for the cultivation of industryeducation integration engineering talents. Most of the current studies on the effectiveness of industry-education integration projects use statistical methods such as factor analysis and regression analysis, which are unable to discuss the holistic role of the combination of influencing factors [15]. This study deconstructs the effective paths to improve the effectiveness of integration projects from multiple perspectives, including enterprise scale, discipline type, and project motivation, using fs QCA analysis, and provides executable and effective special solutions for project implementation. Despite the fact that an effective consensus has yet to be reached, it is clear that the integration of industry and education differs from existing concepts of industry-university cooperation and school-enterprise integration in the following ways: In contrast to "combination" and "cooperation," "integration" is a process in which many different subjects gradually approach each other in terms of cognition and attitude, and eventually become one. In comparison to "combination" and "cooperation," "integration" has a higher intention and places a greater 
emphasis on the relationship and interaction between "production" and "teaching" [16]. It emphasizes the link between "industry" and "education," as well as their interaction and harmony. Based on this, it can be concluded that, in comparison to other expressions, the integration of industry and education is more macroscopic, and the definition of its concept should not be limited to the narrow scope of industry and education, nor should it only consider universities and enterprises, but should be recognized and considered from the macroscopic perspective of structural reform of talents, that is, the "synergy, integration, and even innovation" among multiple subjects such as universities and enterprises. "Synergy, integration, and even innovation" [17] are the core meanings of industry-education integration. Some characteristics of the integration of industry and education can be extracted from scholars' discussions on the connotation: "Plurality" refers to the organic combination of the main bodies and elements to achieve all-round integration, resulting in $1+1>2$ [18]. "Integration" refers to the organic combination of the main bodies and elements to achieve all-round integration, resulting in $1+1>2$ [18]. The term "integration" refers to the organic combination of subjects and elements to achieve all-around integration, resulting in the effectiveness of $1+1>12$; the term "hierarchy" refers to the division of activities between industry and education from various perspectives [19].

\section{Industry-academia-research Integration of Financial Universities in the Greater Bay Area}

3.1. Synergy Theory. It can be seen from the above analysis of the research on the integration of industry and education that the integration of industry and education is more about the synergy between industry and education, emphasizing that the two sides of industry and education, based on the common goal of training engineering talents and other project goals, finally realize the perfect integration of industry and education chains and achieve this through a series of collaborative actions. "Synergy" pervades the entire process of integrating industry and education in the development of engineering talent. This study will use this information to develop a model for training talents in industry-education integration engineering and analyze the path of training talents in industry-education integration engineering using synergy theory as a guide. Igor Ansoff, who introduced synergy into enterprise management in the 1960 s, was the first to propose the concept. When confronted with a potential opportunity, according to Ansoff, businesses must be familiar with their own resources and capabilities and compare them to the potential opportunity in order to determine whether they can develop new business through this opportunity, a process known as synergy. He explained that if all of the subsystems can communicate and coordinate with one another to form an effective collective effect, the overall synergy effect of $1+1>12$ can be generated between them, and each system's role can be maximized. According to synergy theory, organizational system integration is a process in which all elements and subsystems interact with one another to reach a state in which synergistic elements are coupled with one another, resulting in a leap-forward overall amplification effect, which necessitates human active integration behavior.

Synergy is the overall or collective effect of the interaction between various subsystems in a complex and open system, which is a result of synergy. Synergy is the internal force of the system to form an orderly structure, which can make the system at the critical point of qualitative changes and thus produce synergistic effects, so that the system from a disorderly state to an orderly state, and form a stable structure. The order parameter is a macroscopic state parameter that comes from within the system and is introduced to describe the overall behavior of the system and to mark the phase change of the system. When the system approaches a critical point of significant change, the subsystems cooperate with each other to produce new interaction patterns and macroscopic performance, thus forming the order parameter, which also determines the results of competition and cooperation among subsystems to a certain extent. Once the sequential parameters are formed, the system will form a new pattern and evolutionary mode. Selforganization refers to the phenomenon that a system spontaneously exchanges information, material and energy with the outside world without the interference of external forces, and rearranges and combines the system itself to form a new, ordered function or structure, i.e., the system has the characteristic of autopoiesis. Combining the key concepts in the synergistic theory, the evolution process of synergistic system can be expressed as follows: due to the change of the environment in which the system is located, the system has to change its original operation mode and gradually approach to the critical value of change. At the same time, the system will show a variety of modes of operation, which are random combinations of elements and subsystems in the system; the modes will compete with each other, and the final winning mode is the sequential parameter. When the sequential parameters are generated, they have a decisive influence on the operation of the elements and subsystems in the system, and eventually lead to the generation of new system architectures, thus obtaining synergistic effects.

3.2. Fitting of Regional Industrial Structure. This paper extracts the synergistic elements of the integration of industry and education from the case materials, including motivation, incentive, realization, constraint, and feedback mechanisms, and tries to analyze the connotation of each mechanism to further summarize them into project motivation, project action, project constraint, and project effectiveness, and then constructs the model of integration of industry and education using rooted research. In this study, we discovered that when analyzing how to make the industry-education integration engineering talent cultivation project more effective, it is not enough to analyze the independent action or two-way action of each influencing factor, but we also need to use the fs QCA method to investigate the joint action of each factor from the perspective of group state. Meanwhile, the author discovered in his research and case study that the 
strategies used by businesses of various sizes in the industryeducation integration project differ greatly, and that businesses of similar sizes, or even the same company, may use different modes of cooperation to cultivate engineering talent when dealing with disciplines with different attributes (basic or applied). As a result of the rooted findings, this study introduces two condition variables, enterprise scale and discipline type, as condition variables for the integration of industry and education in the development of engineering talents. This study uses enterprise scale, discipline type, project motivation, project action, and project constraint as condition variables, and results in the integration of industry-education projects as outcome variables, based on existing research results and findings. As shown in Figure 1, a research model containing condition variables and outcome variables is constructed from the perspective of synergy theory and used to analyze the operation path of the integration project, with the specific case of the integration of education and industry to cultivate engineering talents as a case study.

Based on the previous discussion on industry-education integration and synergy theory, I found that the main concepts of synergy theory have a certain degree of theoretical transferability to industry-education integration engineering talent cultivation. The synergy theory emphasizes the synergy of elements and subsystems within the system and focuses on the phenomenon of self-organization, which provides a new theoretical basis for system evolution and change, and is a great inspiration for the model construction and path analysis of the integration of industry-education engineering personnel cultivation. The synergy theory is highly relevant in this study, and the specific analysis is as follows: firstly, in terms of the research object, the industryeducation system concerned in this paper is a system far from the equilibrium state, and there will be a non-equilibrium state such as "mismatch between supply and demand". The system is also open and cross-border in nature, and is committed to achieving the synergy of various elements such as financial investment, faculty deployment, curriculum and teaching materials, internship bases, and other subsystems such as industry and education.

\subsection{Identification of Synergistic Elements of Industry-Edu-} cation Integration. Because the conceptual connotation of the synergistic elements of industry-education integration of engineering talents cultivation involved in this study is not yet clear, and because this study is a preliminary exploration of the synergistic mode of industry-education integration, it is necessary to refine and summarize them based on a certain number of case materials in order to answer the question of "what is the synergistic element of industry-education integration of engineering talents cultivation involved in this study?" "What" is the question. Furthermore, case studies are divided into three types: descriptive, explanatory, and exploratory case studies. Exploratory case studies are typically used in the early stages of problem analysis, when it is necessary to have a basic understanding of the research problem in order to lay the groundwork for more in-depth research. Based on this, this paper conducts exploratory case studies based on the original data of several industry-education integration projects in the hopes of discovering the general rules of engineering talent cultivation between schools and enterprises with industry-education integration projects as the focus, in order to develop a conceptual model for the next step of expanding and deepening the practice of industry-education integration, and to systematically improve the theory of in-school integration. In conclusion, the rooting theory is the most appropriate method for this part of the research. Zagan selects a typical case of industryeducation engineering talent cultivation project as a sample, collects first-hand information through field or online research and interviews, collects secondary information such as public information on the Internet, synthesizes the information to form a case database, and applies Strauss' three-stage coding to the case materials using Zagan theory to identify the synergistic elements of the project.

The quality of the research results derived from the analysis using rooting theory is closely related to the quality of the selected cases and the original materials of the cases (See Figure 2). The researcher and his disciplinary team in this paper have conducted tracking research and case collection on the declaration and selection of new engineering projects of the Ministry of Education in recent years, which provided rich research materials and sample sources for this study. The research cases were selected from the excellent projects of the Ministry of Education for New Engineering in recent years1 and the cases on the theme of collaborative education and training between industry and education from the Research Branch of Educational Innovation and School-Enterprise Cooperation of the Chinese Higher Education Society.

$$
Z\left(u_{i}(x), v_{i}(x)\right)= \begin{cases}0, & u=v \\ 1, & u \neq v\end{cases}
$$

After calibrating the data, the adequacy of each condition variable should be analyzed first. In the QCA method, the analysis of the adequacy of individual condition variables is mainly determined by Consistency and Coverage. Consistency is calculated as follows ( $\mathrm{X}$ is the condition variable and $\mathrm{Y}$ is the outcome variable).

$$
\operatorname{Dis}\left(x_{i}, x_{j}\right)=\left(\sum_{i=1}^{n}\left(X_{i}-X_{j}\right)^{q}\right)^{1 / q} .
$$

Consistency is used to determine whether a condition variable (single or combination of condition variables) is necessary (Sufficiency), which is a test of whether the same single or combination of conditions produces the same result from the condition. The higher the consistency, the more the condition variable is sufficient for the outcome variable. The condition variable is considered sufficient for the outcome variable when the consistency value is greater than 0.9 .

$$
X=\frac{X_{i}-\overline{X_{j}}}{\sigma}
$$




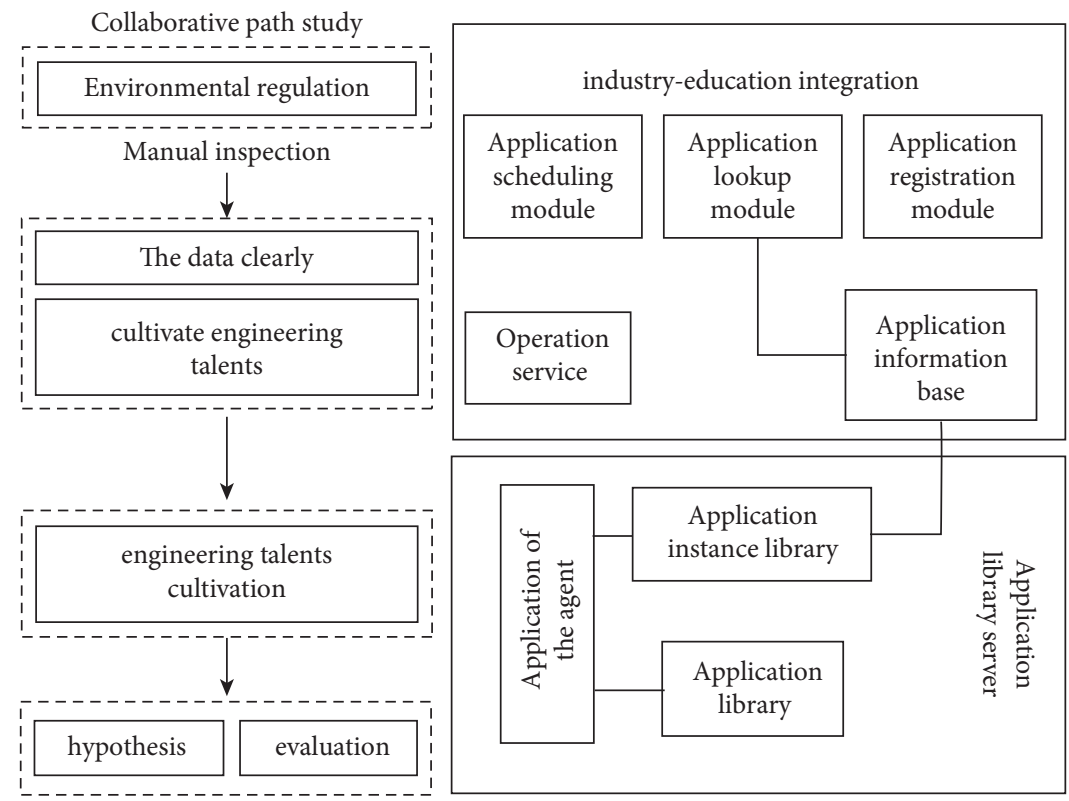

FIGURE 1: Collaborative path study of industry-education integration of engineering talents cultivation.

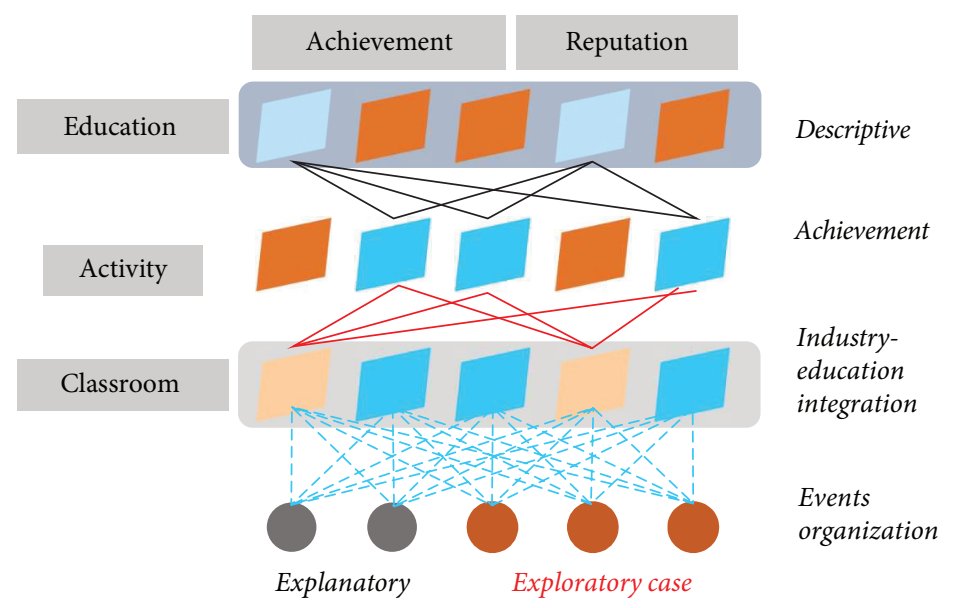

Figure 2: Visualization of coding based on rooting theory.

Importing the truth table into fs QCA3.0 software and taking the positive and negative values of each of the five condition variables once, the results of the necessity analysis obtained are shown in Figure 3. The consistency of all the condition variables did not reach 0.9 when the industryeducation integration project achieved high performance, which indicates that none of the condition variables can be used as a necessary condition for the high performance of the industry-education integration project.

$$
Q(x)=\frac{\sum_{i=1}^{n} p\left(X=x_{i}\right)}{\log _{2}(p(x))} .
$$

The degree of coverage is used to measure the empirical relevance of the necessary condition, i.e., the strength of the explanation of that necessary condition for the outcome variable, and is calculated as follows ( $\mathrm{X}$ is the condition variable and $\mathrm{Y}$ is the outcome variable).

$$
\operatorname{Dis}\left(x_{i}, x_{j}\right)=\left(\sum_{i=1}^{n}\left(X_{i}-X_{j}\right)^{2}\right)^{1 / 2} .
$$

The labeling of case materials is the first task of open coding in the root study, i.e., statements related to the integration of industry-education cultivation of engineering talents are labeled based on the semantics of the materials, which not only lays the foundation for subsequent conceptualization, but also forms the clues for tracing the case materials back to their origin in the future, improving the study's credibility. The focus of this research is on a collaborative model of industry-education integration for the development of engineering talent, and the majority of the cases examined are institutional application materials that are relatively complex in content, with individual case materials exceeding 20,000 words. 


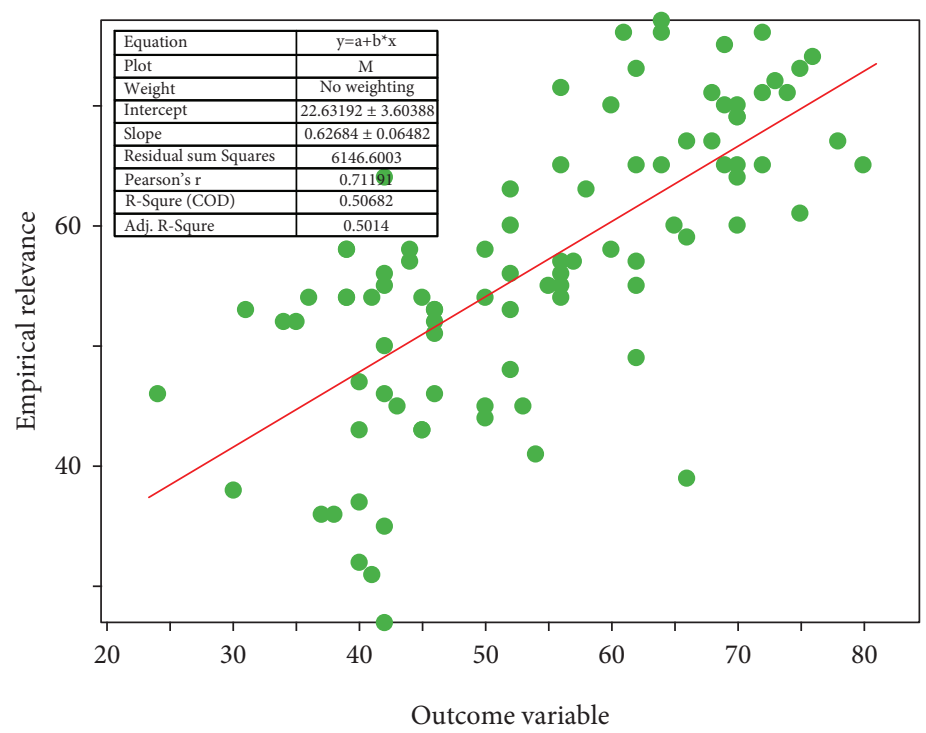

FIGURE 3: Project high performance results.

$$
p(x, y)=\frac{\sum_{i}^{n} q_{i}(x)+p_{i}(x)}{q(x)}
$$

The contents of the case materials related to the integration of industry and education to cultivate engineering talents are analyzed and labeled with the original labels. In the process of labeling, the principle is to always adhere to the objective factual information as the basis and not to make subjective speculations about the case contents, so as to achieve the purpose of restoring the real situation as much as possible. The coding of labeling in this study is in the form of lowercase letters such as "ax," "bx," and "cx" plus a serial number, where the lowercase letters represent different case materials and the serial number The lowercase letters represent different case materials, and the serial number indicates the position of the label in the case to which it belongs.

\section{Research Analysis of the Fit of Industry- education Combination}

The key to further condensing the case material is that the categories formed are related to each other. In the process of categoryization, if it is found that the conceptualized name is already a combination of several properties and dimensions, then it is no longer necessary to abstract it, and it can be directly treated as a category; if it appears that certain categories cannot be found to be related to each other yet, then it is necessary to further increase the case material and enrich the categories on this basis, until a clear vein can be found between the categories to connect them. After labeling, conceptualizing, and categoryizing the case materials, a total of 15 initial categories, including business motivation, school motivation, goal-setting, and academic guidance, were extracted by sampling and comparison. The correspondence between the initial categories and concepts and the relational connotations of the initial categories are shown in Figure 4.

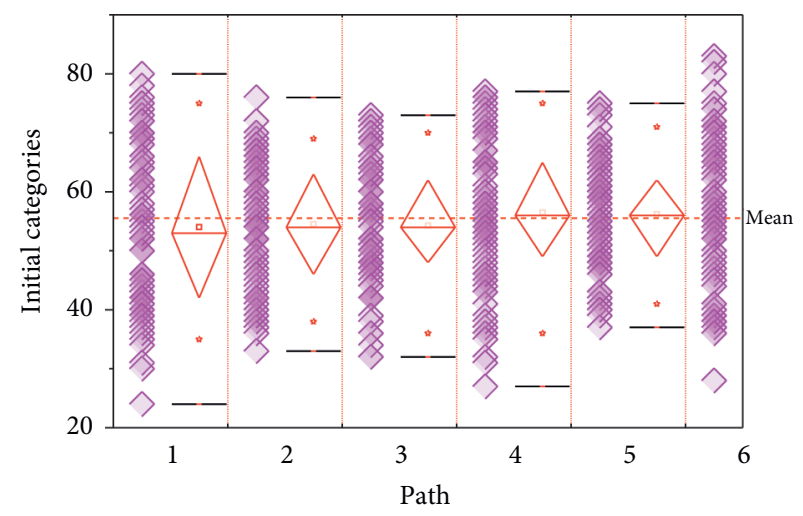

FIgURE 4: Correspondence between initial categories and concepts.

Selective coding is the process of structuring the relationship between the initial categories and extracting the main categories, then delving deeper into the connotation and nature of the main categories to uncover the "core categories," and then presenting the actions of the subjects in the case material using the "story line" around the "core categories." The process of using "story lines" around the "core categories" to present the actions of each subject in the case material. The characteristics of "process," "interaction," and "synergy" of industry-education integration are gradually revealed through open coding and spindle coding. The case materials reveal that, to some extent, the integration of industry-education projects all follow the logic of "antecedent-process-result," as shown in Figure 5. This study classifies the main categories of "motivation mechanism" and "incentive mechanism" into "project motivation" and "formation mechanism" and "realization mechanism" into "project motivation." and "realization mechanism" are classified as "project action," "constraint mechanism" is classified as "project constraint," and "feedback mechanism" is classified as "project effectiveness." "Project action," as a bridge, reflects not only the implementation of project 

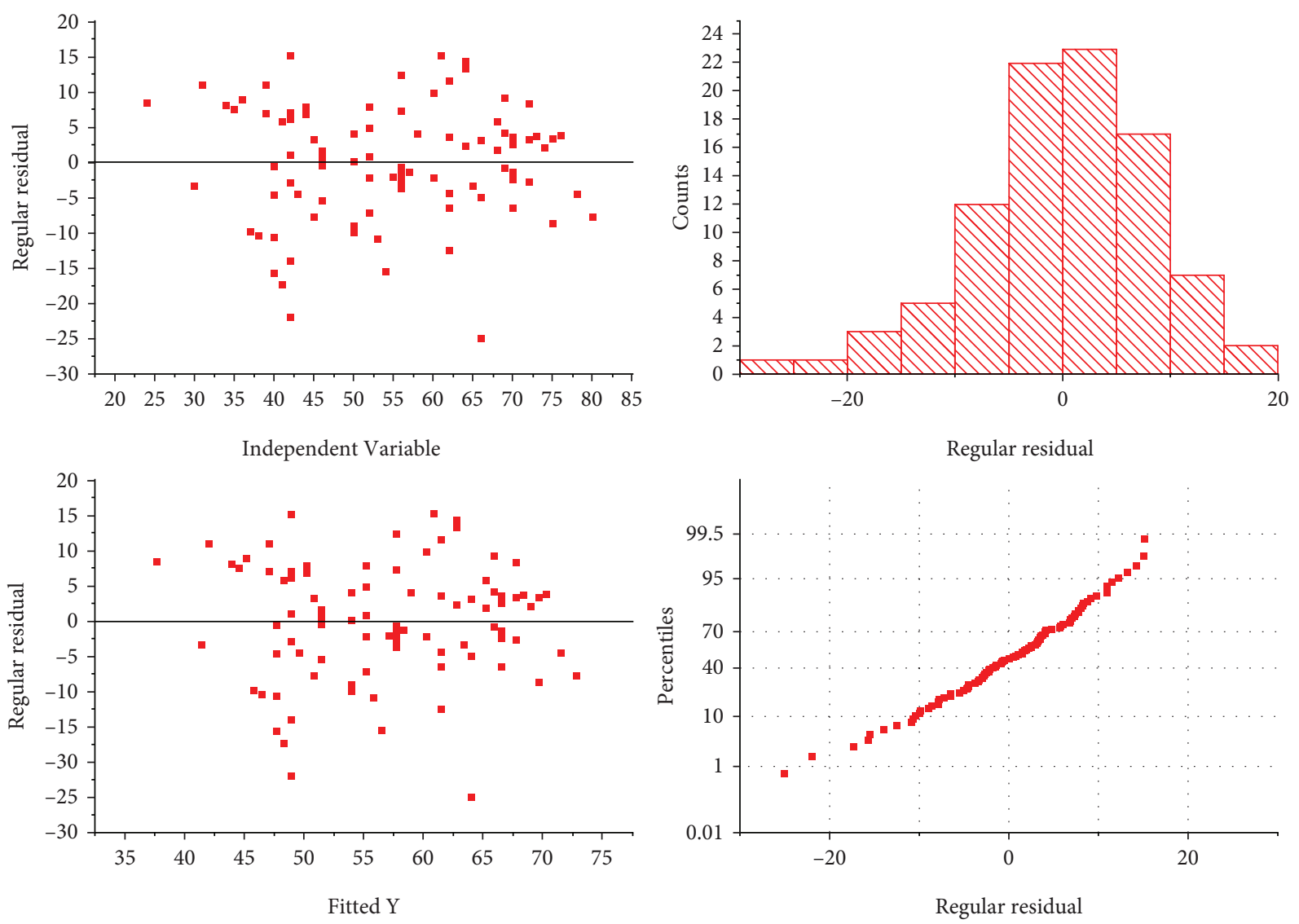

Figure 5: Linear analysis of conditional variables.

motivation, but also the specific practices of both industry and education in cultivating engineering talents through the project, and influences project effectiveness, resembling the core, explanatory, and frequent characteristics required for the core scope. The core category for the training of engineering talents through the integration of industry and education is "project action." In this way, the entire process of industry-education integration engineering talents training project can be reformulated as follows: first, enterprises and institutions form the project based on internal "motivation mechanisms" and "incentive mechanisms" provided by the government and other third parties. The project is formally launched, and project actions such as "formation mechanism" and "realization mechanism," as well as project constraints, are taken as a result of the motivation. The synergy between industry and education is continuously improved under the supervision of the "constraint mechanism," and the project eventually achieves certain results.

Based on the rooting theory, this study identifies six synergistic elements of industry-education integration, including motivation mechanism, incentive mechanism, formation mechanism, realization mechanism, constraint mechanism and feedback mechanism, and analyzes each synergistic element one by one through a three-stage coding of the case materials of industry-education integration. Synergistic element "motivation mechanism". The

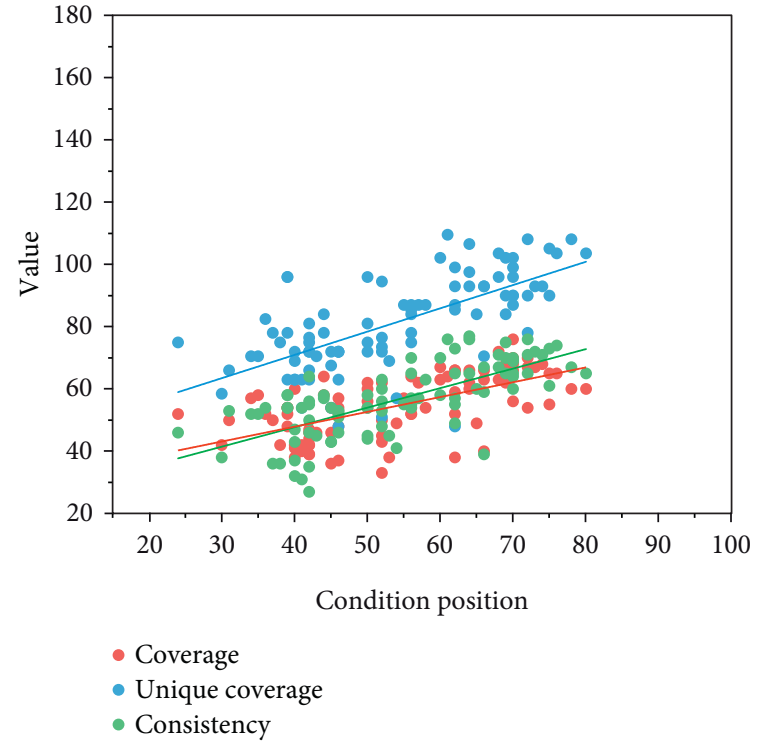

Figure 6: Analysis of complex combinations of solution variables.

motivation mechanism of industry-education integration refers to the fact that the two sides, under the influence of the changing macro environment and business market, based on their own organizational attributes and existing resources, aim to obtain the expected common benefits (i.e., the main purpose of enterprises is to understand the cutting-edge 


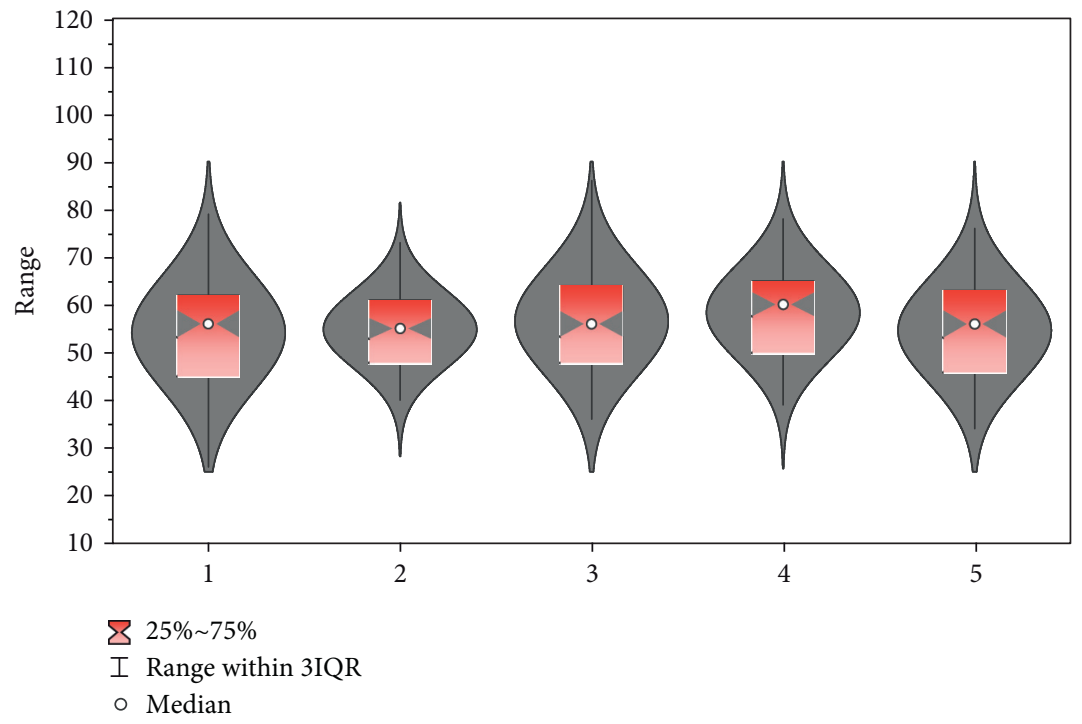

FIgURe 7: Necessity analysis of individual conditions.

knowledge and technology, form commercially realizable results, and reserve future talents for them in response to the development needs of enterprises; while the main purpose of schools is to educate people, i.e., to improve the practical application of students with the help of industry-education integration projects). In general, the interests of the two sides of the industry-education relationship are presented as an "intersection", with differences and overlaps, and they look for subjects with heterogeneous resources to carry out the project, thus transforming the motivation of their respective interests into the project. The sum of the behavioral processes that transform the motivation of each interest into the motivation of synergy. The "incentive mechanism" of the synergy element is shown in Figure 6. The existing cases of industry-education integration often have the phenomenon that enterprises are not highly motivated, i.e., "the school is hot and the enterprise is cold", which leads to the fact that industry-education is still "two-skinned" and cannot achieve the purpose of collaborative training of engineering talents. Therefore, a third-party organization with the government as the core body is needed to stimulate the enthusiasm of both schools and enterprises to carry out the project by giving tax and credit benefits to participating enterprises, providing guidance on the implementation of the project, or even directly providing financial support to the participants.

"Formation mechanism" is a synergy element. This refers to the two parties' preliminary preparations for the synergy. Both enterprises and universities have a strong desire to cooperate in carrying out the industry-education integration project, so both sides have communicated formally or informally for many times, discussed the specific contents, methods, and cycles of the project, until they reach a consensus on the synergy goal, and formed a verbatim agreement. The project is being prepared for the start of the project so that better synergy between the two parties can be achieved during its execution. The synergy element's "realization mechanism." When the industry-education integration project enters the formal implementation stage, as shown in Figure 7, this refers to the process of turning both sides' cooperation intentions into concrete synergistic actions. The first is resource sharing, which includes: first, the two sides investing funds jointly to support the implementation of various project activities; second, the sharing of sites and equipment, in which enterprises provide sites and equipment for students to practice so that they can be more fully exposed to real engineering scenarios, and schools provide on-campus sites and some advanced equipment to enterprises to help them achieve technological breakthrou; and third, the sharing of knowledge, which includes: enterprises providing sites and equipment for students to practice so that they can be more fully exposed to real engineering scenarios Third, manpower sharing, in which enterprise instructors participate in the design of students' training programs, the development of curriculum and teaching materials, classroom lectures, and assist project students in grasping the direction of their chosen topics as well as provide internship practice opportunities, while university teachers also go into enterprises to train students and solve enterprise problems in real-world production scenarios.

The questionnaire data from the Likert scale used in this study have a natural advantage over qualitative data in terms of data calibration. However, when the distribution of the collected questionnaire data is skewed due to a small sample or respondent bias (e.g., for a four-level scale, the answers to some questions are distributed between 3 and 4), the scale and the sample are not calibrated. However, when the distribution of the collected questionnaire data is skewed due to small sample size or respondent bias (e.g., some items in the four-level scale are distributed in 3 and 4), i.e., the scale is not consistent with the sample distribution, the researcher needs to deal with the relationship between the two. In recent years, scholars have dealt with such problems mostly by the proposed method of taking the 


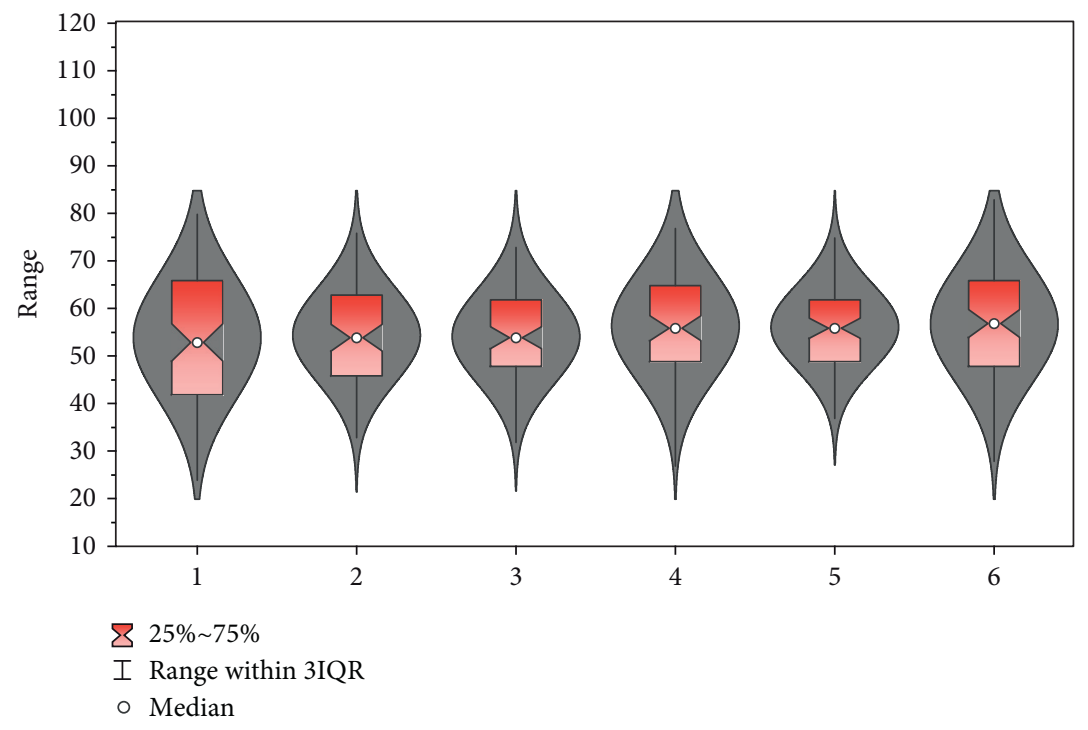

FIgURE 8: fsQCA data calibration.

percentile of the sample data, i.e., the $95 \%$ percentile, $50 \%$ percentile, and $5 \%$ percentile of each variable as its full affiliation point, crossover point, and full unaffiliated point, respectively. The crossover point is the point at which the fuzziness (fuzziness) of whether a case belongs to a certain set is greatest when it is at that point, and such cases are often not included in the analysis because they are difficult to categorize, which in turn affects the analysis results. Therefore, in order to avoid the crossover value being ignored, a small adjustment is made to the crossover point by adding or subtracting a small number such as $1 \%$ or $0.1 \%$ from the $50 \%$. This paper also follows the above approach for the four variables of project motivation, project action, project constraint, and project effectiveness, and the final specific calibration results obtained are shown in Figure 8.

Second, the platform is jointly developed, with the following three types of platforms being jointly developed by industry and education: First, universities will undertake some horizontal projects that require the use of enterprise resources, and likewise, technological innovation of enterprise products also necessitates the participation of school research forces, and these two sides will collaborate to build a project platform that provides more diversified options for students and can meet their own development needs; second, practice platform, which actually takes the form of a practice platform, which provides more diversified options for students and can meet their own development needs; and third, practice platform, which takes the form of a practice Third, communication platforms, such as online and offline seminars, academic conferences, regular project meetings, and so on, which are conducive to synchronizing project progress, discussing and solving project problems together, and further exploring demand points for industry-education cooperation; and fourth, practice platforms, such as online and offline seminars, academic conferences, regular project meetings, and so on, which provide students with opportunities to get in touch with real engineering scenarios, discover and solve real engineering problems; and fifth, practice platforms, such as online and offline seminars, academic conferences, fourth, there is coordination. The fourth platform is the coordination platform, which includes groups such as the leadership group and the coordination group, and promotes efficient and organized communication between industry and education. Finally, the school and the enterprise collaborate in the co-education of students, which is manifested in the form of designing training programs for project students, developing curriculum and teaching materials, establishing a dual mentorship system, providing internship opportunities for students, and guiding their thesis, which is manifested in the form of designing training programs for project students, developing curriculum and teaching materials, establishing a dual mentorship system, providing internship opportunities for students, and guiding their thesis.

\section{Conclusion}

In this paper, I use the root theory approach to identify 43 concepts, 15 initial categories, and 6 main categories from the original case materials of industry-education integration; second, I explore the story line of "project motivationproject action-project constraint-project effectiveness" on this basis; and finally, I examine the meaning of each synergistic element and its implications. Finally, each synergy element's meaning and interconnection are examined. The next step is to develop a comprehensive and dynamic synergy model that incorporates all synergy elements and can assist in the development of industry-education integration projects, in order to provide more systematic guidance for the cultivation of engineering talents in industry-education integration projects and to effectively improve the quality of engineering talents cultivated in industry-education integration projects. This paper examines the similarity of integration projects using a 
questionnaire survey and the fs QCA research method, analyzes the combination of various elements that can improve project effectiveness, and proposes feasible paths for different types of universities and businesses to cultivate engineering talent. Suggestions. We discuss the project of integration of industry-education engineering talents cultivation systematically, identify the synergistic elements of integration of industry-education engineering talents cultivation, and construct a synergistic model of integration of industry-education engineering talents cultivation based on synergy theory, which enriches the theoretical connotation of integration of industry-education and expands the research scope of topics related to integration of industryeducation engineering talents cultivation.

\section{Data Availability}

The data used to support the findings of this study are available from the corresponding author upon request.

\section{Conflicts of Interest}

The authors declare that they have no known competing financial interests or personal relationships that could have appeared to influence the work reported in this paper.

\section{Acknowledgments}

This study did not receive any funding in any form.

\section{References}

[1] M. A. Apie, L. U. Akah, J. O. Ogabor, A. A. Usoro, and J. Upkong, "Financial management, motivation and the teaching effectiveness of physical education lecturers in colleges of education in south-south Nigeria," The Journal of Social Sciences Research, vol. 7, no. 3, pp. 145-151, 2021.

[2] W. C. Boland, "Performance funding and historically black colleges and universities: an assessment of financial incentives and baccalaureate degree production," Educational Policy, vol. 34, no. 4, pp. 644-673, 2020.

[3] P. M. Carrera, H. M. Kantarjian, and V. S. Blinder, "The financial burden and distress of patients with cancer: understanding and stepping-up action on the financial toxicity of cancer treatment," CA: A Cancer Journal for Clinicians, vol. 68, no. 2, pp. 153-165, 2018.

[4] A. Y. Chang, K. Cowling, A. E. Micah et al., "Past, present, and future of global health financing: a review of development assistance, government, out-of-pocket, and other private spending on health for 195 countries, 1995-2050," The Lancet, vol. 393, no. 10187, pp. 2233-2260, 2019.

[5] S. Corbet, A. Meegan, C. Larkin, B. Lucey, and L. Yarovaya, "Exploring the dynamic relationships between cryptocurrencies and other financial assets," Economics Letters, vol. 165, pp. 28-34, 2018.

[6] J. Coupet, "Exploring the link between government funding and efficiency in nonprofit colleges," Nonprofit Management and Leadership, vol. 29, no. 1, pp. 65-81, 2018.

[7] S. Eide, "Private colleges in peril: financial pressures and declining enrollment may lead to more closures," Education Next, vol. 18, no. 4, pp. 34-41, 2018.
[8] C. A. Elue and E. Martinez, "Show me the money: examining institutional-based financial aid for baccalaureate degreeseeking students at rural community colleges," Community College Journal of Research and Practice, vol. 43, no. 5, pp. 382-385, 2019.

[9] D. Khullar, A. M. Bond, and W. L. Schpero, "COVID-19 and the financial health of US hospitals," JAMA, vol. 323, no. 21, pp. 2127-2128, 2020.

[10] J. Koh, S. G. Katsinas, and N. J. Bray, "State financing for public community colleges: a comparative study of fiscal capacity and tax effort," Journal of Education Finance, vol. 45, no. 2, pp. 198-216, 2019.

[11] I. Lee and Y. J. Shin, "Fintech: ecosystem, business models, investment decisions, and challenges," Business Horizons, vol. 61, no. 1, pp. 35-46, 2018.

[12] A. Muñoz-Miquel, “Assessing how closely postgraduate translation programmes fit the reality of professional practice: a case study of the Spanish context," Interpreter and Translator Trainer, vol. 12, no. 1, pp. 89-109, 2018.

[13] P. S. M. Nolan, "Higher education product baskets: degree offering distributions and the financial strength of colleges and universities," Business and public administration studies, vol. 15 , no. 1, pp. 24-30, 2021.

[14] O. Okorie, O. U. Onwe, and L. O. Unugo, "International financial reporting standards (IFRS) education in colleges of education in southeastern states of Nigeria," American Journal of Educational Research, vol. 6, no. 11, pp. 1460-1464, 2018.

[15] I. W. Park, "Liberal Arts Colleges in their own sake, can we have them in Korea?: new agenda for RIGHT governmental financial support," Episteme, vol. 22, pp. 35-57, 2019.

[16] C. Salinas and J. R. Hidrowoh, "Promoting financial literacy and latino males' success at community colleges," Community College Journal of Research and Practice, vol. 42, no. 5, pp. 330-339, 2018.

[17] W. H. Shrank, T. L. Rogstad, and N. Parekh, "Waste in the US health care system: estimated costs and potential for savings," JAMA, vol. 322, no. 15, pp. 1501-1509, 2019.

[18] M. A. Titus, "Examining degree production and financial context at public master's colleges and universities in the United States: a distance function approach," Tertiary Education and Management, vol. 26, no. 2, pp. 215-231, 2020.

[19] M. Turkanovic, M. Holbl, K. Kosic, M. Hericko, and A. Kamisalic, "EduCTX: a blockchain-based higher education credit platform," IEEE Access, vol. 6, pp. 5112-5127, 2018. 